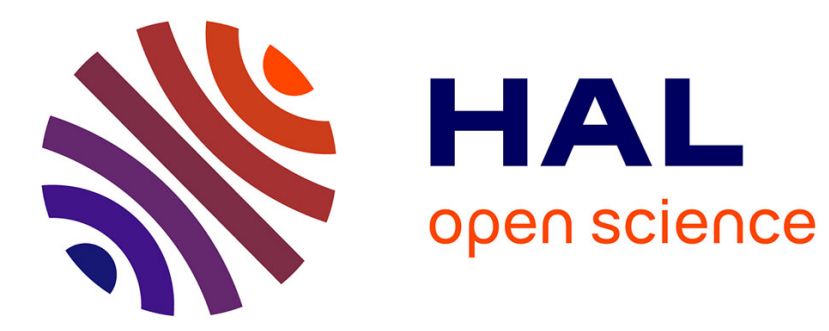

\title{
Reinventing classics: the hidden design strategies of renowned chefs
}

Marine Agogué, Armand Hatchuel

\section{To cite this version:}

Marine Agogué, Armand Hatchuel. Reinventing classics: the hidden design strategies of renowned chefs. Research in Engineering Design, 2015, 27, 10.1007/s00163-015-0210-3 . hal-01252978

\section{HAL Id: hal-01252978 \\ https: / hal-mines-paristech.archives-ouvertes.fr/hal-01252978}

Submitted on 15 Feb 2017

HAL is a multi-disciplinary open access archive for the deposit and dissemination of scientific research documents, whether they are published or not. The documents may come from teaching and research institutions in France or abroad, or from public or private research centers.
L'archive ouverte pluridisciplinaire HAL, est destinée au dépôt et à la diffusion de documents scientifiques de niveau recherche, publiés ou non, émanant des établissements d'enseignement et de recherche français ou étrangers, des laboratoires publics ou privés. 


\title{
Reinventing classics: the hidden design strategies of renowned Chefs
}

\author{
Marine Agogué(1), Armand Hatchuel ${ }^{(2)}$ \\ (1) HEC Montréal \\ (2) Centre de GestionScientifique, Mines ParisTech, France
}

\begin{abstract}
Reinventing classics is a well-used yet complex design pattern. Indeed, a reinterpreted classic needs to relate to the original object while simultaneouslychallenging the initial model and providinga new and fresh look tothe well-established classic. However, this design strategy remains understudied, and we aim to contribute to the literature by addressing the lack of theoretical models for reinventing classics.

Reinterpreting tradition is a key process for chefs in the culinary world.Our paper explores how design theories elucidate how chefs reinterpret classics and innovate in their kitchens by stepping away from tradition. Our contribution to the study of design is twofold.First, from a methodological point of view, we used a framework based on $C-K$ theory and axiomatic design theory to conduct a comparative analysis of recipes for 30 dishes that were reinterpreted by the renowned chef Alain Ducasse. Second, our study identifiedtwo design regimesused by chefs to reinvent classics by focusing on the nature of the set of functions a recipe aims to fulfill. The first regime consists of retaining the same functionsfrom the original recipewhile changing themeans to achieve them. The second requires changing the set of functionsby removing old ones, adding new ones and occasionally designing new ways to achieve the functions.
\end{abstract}




\section{Introduction: modeling culinary innovation}

Reinventingclassics is a well-known design strategy used in many fields: Fiat redesigned the myth of the Fiat 500, Picasso proposed his own version of Manet'sLuncheon on the Grass, and Murakami drew cherry blossoms on the iconic Louis Vuitton Speedy handbag. Fashion cycles and recycles, and reinventing classics has become a regular patternin the design of new products and/or services, thus expanding the current understanding of the role old technologies may play in innovation processes (MesseniPetruzzelli, Rotolo, \& Albino, 2012; Katila 2002; Nerkar, 2003). And because innovation can be considered as a process of recombining existing elements (Nelson and Winter, 1982), building on the reuse of existing knowledge (Majchrzak, Cooper \&Neece; 2004), and even sometimes the reuse of previously dismissed ideas (Capaldo, Lavie\&MesseniPetruzelli, in press), reinterpreting classics is a paroxysmal situation of design in all fields.

Besides, the outcome of areinterpretation process is often presented as an innovation, which highlights a paradox arising from the connection between tradition and innovation: a reinterpreted classic on the one hand relates to the original design,whileon the other hand, it challenges the initial model by changing features and creating surprises.Thus, reinterpreting a classic requires articulating both innovation and tradition to relate to the classic andto make room for a truly novel proposal. Specifically, the line that defineswhen an object ceasesto be a classic and becomes an innovation is a blurry one. It appears that this particular phase of reinterpretation-driven ideation is poorly understood yet extensively used, all the more so given that designers' efforts to produce something new are typically anchoredintheir capacity to reuse existing knowledge while simultaneously exploring new knowledge (Katila\&Ahuja, 2002). Thus, there is a need to build a theoretical framework that objectifies the distance between the reinterpretation of a classic and its original form. 
Reinventing a classic dish is a design strategy in the culinary industry in which chefs reinterpret, for example, the classics of French or Asian cuisine. In this specific context, classics have a significant aura, especially when they are reinterpreted in a new, modern way (Stierand,Lynch \&Dörfler, 2011). A small number of case studies have proposed insights into the idea generation processes of different chefs (Svejenova, Mazza and Planellas, 2007; Rao et al., 2005; Leschziner, 2009; Messeni,Petruzzelli\&Savino, 2012). Specifically,Messeni,Petruzelli and Savino (2013) proposed a model for reinterpreting tradition to innovate in cooking. They argued that to reinterpret tradition to innovate, a chef creates novel product architectures, recombining the old components by introducing new elements. This process representsa pioneering approach to culinary design, and the study highlighted the need to investigate the resources at chefs' disposal, either in terms of the components (ingredients, techniques, etc.) or in terms of their integration.

Deepening this perspective, understanding the design strategies developed by chefs for reinterpreting traditional recipescan be investigated in two different ways: first,we may capture the"reinterpretation" of a recipe by analyzingthe parameters that have been mixed together. However, such an approach would miss the intent behind the recipe. The second approach would require thatwe follow contemporary design theory, whichtakes into account the will and the aim of the chef based on the modeling on the final design in order to infer the hidden design strategies that were mobilized by the chef.Following this pathmeans introducing a functional language to the analysis of recipes without being "functionalist," i.e., without assuming that all chefs target the same repertoire of functions. Fortunately, contemporary design theory offers a flexible view of "functions" and invites us to see "functions" as a domain in which chefs can also invent.Indeed, althoughcurrent studies do not provide a model of chefs' design strategies that encompasses the resources they use as well as the different"functions" a recipe aims to fulfill, recent design theories have provided frameworks and theoretical elements for modeling design activities. 
Therefore, the research question in this paper is as follows:How can design theory models help us to understand the way(s)in which chefs reinterpret classic recipes and innovate by stepping away from tradition?Specifically, C-K theory has shown its potential to relate to other design theories (Kroll, Le Masson \& Weil, 2014). Building on an analysis of recipes both from traditional French culinary courses and from the renowned French chef Alain Ducasse, we demonstrate in this article how different design theories-axiomatic design theory (Suh, 2001) and C-K theory (Hatchuel\& Weil, 2009)-help to model the culinary design strategies that occur during the reinvention of classics in hautecuisine. We specifically chose the case of Alain Ducassebecause he is one of the most famous chefs, currently holding 21 Michelin stars, who took great care in explaining his activities: he wrote many books and repeatedly described his own cooking process, thus providing researchers extensive material to investigate.

This paper is structured as follows: first, we emphasize the relevance of reinventing classics to design studies. Second, we present the different streams of research that have examined culinary innovation and culinary creativity. The literature primarily investigatesthe idea generation processes and focuses on the recipe and the resources aligned to fulfillthe recipe as the coreartifactof the idea generation process. Innovating in a culinary context means designing a new dish and therefore requires designing a recipe or, in certain cases, redesigning a classic recipe. Third, we propose a theoretical framework that combines design theory approachesand leads to the introduction of a functional language for culinary design. We show that these design models help to objectify different regimes for what is called the "reinterpretation of a classic". We then present the material that we use in our study: a comparison of two different sets of recipes (the classics that are taught in France and their innovative redesign by the chef Alain Ducasse) thatreveals the diversity of means for reinterpretation used by chefs. We reveal our results, and our study identifies two design regimesused by chefs to reinvent classics; however, these strategies only appear if we also 
take into account the set of functions a recipe aims to fulfill (such as a sweet taste or meltingly soft beef). The first regime consists of preserving the same functions of the original recipe while changing the means to achieve them. The second requires changing the set of functions by removing old ones,adding new ones and occasionally designing new ways to achieve the functions. We conclude by discussing a new understanding of culinary design, and we further propose insights regarding general design principles for reinterpreting classics in broader contexts.

\section{Literature review}

\subsection{Redesigning classics}

Innovation has been considered to be a process of recombining existing elements (Nelson and Winter, 1982). Even the most radical innovation builds on the reuse of existing knowledge (Majchrzak, Cooper \&Neece; 2004), and sometimes, new ideas are simply old ones that were once dismissed (Capaldo, Lavie\&MesseniPetruzelli, in press). This reuse is necessaryfor both the process of designing a new object—which requires building on existing knowledge - and for the reception of the new object by the audience (customer, user, buyer, etc.).Katila (2002) proposed that old extra-industry knowledge can very effectively promote innovation by deepening the absorption capacity view to include older external knowledge as a source of new ideas, as knowledge that has been explicated for a longer time is usually more reliable, more legitimate and decreases the threat of retaliation from the initial creators of the knowledge.

From the audience perspective, two aspects relate a new object to existing knowledge. First, marketing studies have shown that there is growing and renewed interest in products that rediscover the "past" (Brown, Kozinets\& Sherry, 2003). Second, and most important, is the fact that a new object needs to be recognized.Faerber and Carbon (2014) showed that 
imitators who reinterpret novel features in a product are more likely to be accepted by customers when they look very similar to the original product in addition to copying a specific novel feature. In other words, the previously unknown object must be immediately recognizable(Hatchuel, 2013), which implies thatthe newly designed object relates to a world of meaning, to existing knowledge, and to stable identities of known designs.

Even if some stability is required, there is always distance between a new design and the set of existing objects. This distance can be found in the departure point of the design process, i.e., the thinking process at the "very early stage of design" (Taura\& Nagai; 2013). A classic could be randomly reinvented, but there is also a systematic will of the designer to create that distance by rethinking a well-known, well-established object. Yet, a paradox arises from the interplay between a classic and an innovatively designed object: how can a reinterpreted classic be related to the original object while at the same time challenging the initial model andproviding a new, fresh look to a well-established design?

\subsection{Ideation in culinary design}

On the specific topic of culinary design, research has focused on the art of culinary innovation byuncovering how chefs exploit product seasonality as well as diverse sources of inspiration whendesigning new dishes (Ottenbacher\& Harrington 2007a). Similar to designers in engineering fields (Sarkar\&Chakrabarti, 2014), searching for ideas is a major activity of chefs. More precisely, Harrington (2004) argued that analyzing the development of new recipes requires studying four main topics: the use of scientific knowledge about perceptions; taking advantage of the scientific knowledge about food composition and properties; the use of nontraditional ingredients and knowledge regarding their culinary uses; and the useof industrial and scientific technologies that are far from traditional culinary technologies (Ruiza,Calvarroa,Sánchez, Roldána, 2013). However, Stierland and Lynch (2008) suggested that this approach to culinary innovation remains quite restrictive, and they argued that this 
line of work (Harrington, 2004; Ottenbacher\& Harrington, 2007b) provides a generic "continuous innovation process" while ignoring the fuzzy dimensions of culinary innovation, such as the worlds that elite chefs live in or the collective learning process that occurs within a culinary movement (Stierland\& Lynch, 2008). Typically, the question of the resources gathered during the idea generation phase is raised (Stierland\&Dörfler; 2011).

A small number of case studies have proposed insights into the idea generation processes of different chefs. Typically, Svejenova, Mazza and Planellas studied the creative process of the famous chef FerranAdrià (2007). The authors highlighted how new concepts and new techniques are at the core of Adrià's creative thinking. The chef indeed plays with the different attributes of a dish, such as the texture, the form, and the taste. Specifically, the authors suggested that one creative endeavor is deconstructing a dish, which consists of altering the properties of a well-known recipe to introduce the chef's style into the reinterpretation of a classic. For instance, FerranAdrià proposed the "Kellogg's paella" recipe, which is a reinterpretation of the classic paella as a two-sided dish incorporating a paella soup and Kellogg's saffron rice, breakfast style (Svejenova, Mazza and Planellas, 2007).In a study of the French nouvelle cuisine movement of the 1970s (Rao et al., 2003), the rules of cooking used by the nouvelle cuisine chefs were described in contrast with the principles of Escoffier that were used in traditional cooking. The rules of cooking in the nouvelle cuisine movement featured using new ingredients, mobilizing new cooking techniques and twisting old ingredients and techniques in new ways. In another case study of the Danish chef René Redzepi, Petruzelli and Savino (2012) stated, "new dishes are always characterized by blending past and present, tradition and modernity."

Thus, scholars have highlighted that one crucial aspect of culinary creativity relies on reinventing classic recipes by recombining old and traditional components and changing the interpretation of the dish (Petruzzelli\&Savino, 2012; 2013). This emphasis is in line with the statement byLeschziner (2009) thatthe combined pressures of tradition and innovation 
introduce constraints and heavily influence the dishes chefs create: "These chefs would see tampering with traditional recipes as an attempt to be original for the sake of originality, or as they call it, for the "wow factor." Tampering with traditional recipes may take the form of substituting classic ingredients with others that are new or faddish, or using fashionable cooking techniques to change the textures of ingredients" (Leschziner, 2009).

Petruzelli and Savino (2013) proposed a model for reinterpretingtradition to innovate in cooking based on interviews and direct observations of five Italian restaurants that were awarded three Michelin stars. They argued that to reinterpret tradition to innovate, a chef creates novel product architectures in which the old components primarily characterize their temporal and geographic identity and are recombined by introducing new elements.More precisely, the authors characterized two primary strategies: (1) old components may be recombined with novel components from unfamiliar and distant fieldsthat contributeby enhancingthe variety and scope of recombination, which in turn may increase the likelihood of creating valuable products; and (2) renewed productsthat rely upon old components may be created by developing unusual recombinations, thereby "offering unexpected solutions that derive from putting into close proximity elements generally considered as isolated and thus contributing to translate "tradition" into "modernity" "(ibid). This is a pioneering approach to culinary design, and the study highlighted the need to investigate the resources at a chef's disposal, either in terms of the components (ingredients, techniques, etc.) or in terms of their combination. Pursuing this path, a number of questions must still be investigated: Are there designstrategies developed by chefs when reinterpreting traditional recipes? Is a reinterpretation only a matter of mixing parameters together, or could a model of such design strategies take into account the will or the aim of the chef? To the best of our knowledge, the literature does not provide an explanatory framework for these issues.

\subsection{Recipes as the focus of idea generation}


What can be gathered from the different studies is that the recipe and the resources aligned to fulfill it have been considered to bethe core of the idea generation process. Indeed, the recipe simultaneously represents the set of variables at the chef's disposal, the tradition evocated by the title of a dish and the design that the chef aims to achieve. If we look more closely, the recipe is a very old object that has hardly changed in form in over 800 years. Today, recipes play a complex role, and chefs use them in different ways. Indeed, some may use a recipe as technical knowledge, whereas others read recipes to find inspiration. Writing down a recipe is also a way to make the culinary design strategy explicit: today, many chefs write books to pass on their know-how. The goal is to write a recipe to reduce a dish to its essence: it is a sequence of elementary tasks thought to simplify the execution of a dish and decrease the level of knowledge and expertise needed from the person who will be making the dish. The recipe should leave no room for imagination or interpretation. It aims therefore to simultaneously reduce the required skillswhile encompassing the chef's will in terms of taste, texture, ingredients, techniques, etc. Innovating in a culinary context means designing a new dish and therefore requires designing a recipe or,in our case, redesigning a classic recipe.

However, a recipe is only the construction process for a culinary innovation;it should not be confused with the entire rationale of a design process. In the study of culinary design, one way to address the topic is to study the design process through the involvement of actors, the prototyping and testing of dishes, evaluation and self-evaluation, etc. However, our question is not whether chefs working on tradition have a different process than other chefs; our aim is to characterize the design strategies adopted by chefs regarding tradition and the reinvention of tradition, and the recipe is the relevant proxy to do so because it encapsulates the design strategy. Our approach is thus the equivalent of discussing architectural solutions in the study of architectural design: the challenge is not to look for the work of the architect but to analyze the architectural strategies he/she adopts. In that sense, our goal is to adopt a 
methodological approach that allows us to infer an understanding of a design process or a design strategy from knowledge of the final artefact alone.

Most design theories assume that design is guided by some desired impact or properties. These can be precise requirements, qualitative ideals, broad judgments or subjective perceptions. Some design "functions" can be established by the designer,by his or her clients, or by both, andthey help the designer select from among the variety of potential combinations. Thesefunctions can also be considered inventions per se when the designer creates new aims and values for his/herwork. Using functions will help us model the logic of culinary innovationsin a more complete way.

\section{Introducing culinary functions: a theoretical framework for analyzing the design of classic reinventions}

Current studies do not provide a model ofachef's design strategies in the case of reinventing tradition. However, recent design theories have provided frameworks and theoretical elements to model design activities. They provide a frameworkfor understanding the "functions" of design, thus acting as theoretical devices for explanation. In the case of culinary design, the notion of "function" needs to be clarified: if traditionally the notion of function falls within the tradition of engineers, the concept of function can still be extended to artistic design. If the purpose is to cause fresh feeling for the person who eats a certain dish, we then call "function" the created sensation. Thus emerge functions that play the role of the functional requirements described in design theories, but the functions do not concern conventional kitchen indicators (i.e., nutritional value): the notion of function we mobilize here is not a nutritional function but a gastronomic function.

As our research purposein this paper is to understand the ways in which chefs reinterpret classic recipes, we can start by stating the requirements for a theoretical framework 
that would enable a deepeningof the current understanding of chefs' design activities. First, we need tomodel the reasoning behind a recipe, whether traditional or creative. Therefore, we need to mobilize thetheoretical elements that provide for a model of design reasoning and account for original designs. Second, we need to compare different recipes for the same dish and account for the resources and the functionseach recipe aims to achieve, which therefore require a framework for comparing different recipes.

First, concept-knowledge design theory (C-K theory) models creative reasoning (Hatchuel\& Weil, 2009; Le Masson, Weil\&Hatchuel, 2010; Reich, Hatchuel, Shai, \&Subrahmanian, 2012; Agogué\&Kazakçi, 2014). As such, it seems relevant to use this approach to model the reasoning behind a recipe, whether traditional or creative. More specifically, C-K theory has shown its potential to not only describe the existing paths of creative solutions but also to model the generation of ideas outside of existing paradigms. C-K design theory allows for modeling the creative process as the interrelated expansion of two spaces (Hatchuel\& Weil, 2009): the concept space (C-space) is tree-structured and describes the progressive generation of alternatives, and the knowledge space (K-space) is formed by the network of knowledge used to generate concepts in the C-space. Therefore, C-K theory proposes a framework for a design process based on refining and expanding an initial concept by adding properties stemming from the K-space. It offers a means to characterize different paths of solutions and the pockets of knowledge associated with the different sets of solutions. This type of theoretical framework provides a way to model each recipe, and it associates the different resources (in the K-space) needed with each step of the design process (in the C-space).

To compare different recipes, one of the primary advances in design theoryfrom the 1990s by Nam P. Suh (2001), namely, the theory of axiomatic design, bears promise. This approach aims to characterize the quality of a design. In this context, Suh proposedusing a two-dimensional matrix to represent the relationship between two types of variables for an 
object that is to be designed, namely, the functional requirements and the design parameters. The functional requirements are the set of independent requirements that completely characterize the functional needs of the design solution in the functional domain. The design parameters are the different elements of the design solution in the physical domain as they are selected to satisfy the specified functional requirements. This theoretical frameworktherefore allows for comparing two recipes for the same dish and contrasting the mobilized design parameters as well as the design aim by eliciting the functional requirements.

To account for a model of reinterpreting classics, we propose a theoretical framework that encompasses elements from $\mathrm{C}-\mathrm{K}$ theory and from axiomatic design theory (see the synthesis in Figure 1). From an original dish (i), two objects coexist: the traditional dish, encompassed in the recipe $\mathrm{TR}_{\mathrm{i}}$, and the reinterpretation of the dish by Alain Ducasse, embedded in the recipe $\mathrm{AD}_{\mathrm{i}}$. Each recipe contains a series of ingredients and a list of elementary steps to produce the dish. Using a C-K theory model, each recipe can be considered to be a conjunction starting from an initial $\mathrm{C}_{0}$ and adding, stepwise, different properties to the initial concept. Hence, each recipe is thepairing of a path in the $\mathrm{C}$-space $\left(\mathrm{C}_{0} \cap\right.$ $\left.\mathrm{P}_{1} \cap \ldots \cap \mathrm{P}_{\mathrm{N}}\right)$ with the associated pockets of knowledge $\left\{\mathrm{K}_{\mathrm{i}}\right\}$ needed to account for the different properties mobilized in the C-space. Among the different pieces of knowledge in the $\mathrm{K}$-space, we can focus on those that define the primary functions $\left\{\mathrm{F}_{\mathrm{i}}(\mathrm{K})\right\}_{\text {of }}$ the recipe. $\mathrm{C}-\mathrm{K}$ theory allows for a dynamic view of these functions (Hatchuel\&Weil, 2009) thatcan be generated during the design process itself. Therefore, innovation can result from inventing a new function, for instance, new aesthetic values or new tastes. Thus, using a C-K modelfor each recipe, the classic and its reinterpretation can be considered to be

$$
\begin{aligned}
& \mathrm{TR}_{\mathrm{i}}=\left(\left\{\mathrm{F}_{\mathrm{i}}(\mathrm{K})\right\} ; \mathrm{C}_{0} \cap \mathrm{P}_{1} \cap \ldots \cap \mathrm{P}_{\mathrm{N}}\right) \\
& \mathrm{AD}_{\mathrm{i}}=\left(\left\{\mathrm{F}^{*}{ }_{\mathrm{i}}\left(\mathrm{K}^{*}\right)\right\} ; \mathrm{C}_{0} \cap \mathrm{P}^{*}{ }_{1} \cap \ldots \cap \mathrm{P}^{*}{ }_{\mathrm{N}}\right) .
\end{aligned}
$$

Building on that first step, a comparison of the two recipes emphasizes that both recipes depart from the same initial concept. Then, the distance between a classic and a 
reinterpretation can be seen as the distance between the two paths, i.e., the number of expansions of the reinterpreted path from the initial concept with regard to the original recipe. Furthermore, any addition or subtraction of a function in the recipe will influence the set of functions $\left\{\mathrm{F}_{\mathrm{i}}(\mathrm{K})\right\}$. Thus, to expand beyond this first step, comparing the two recipes relies on the capacity to compare the functional requirements and the design parameters of both. Therefore, relying on Suh's proposal for modeling existing objects, the previous model can be reshaped into a set of functional requirements $\left\{\mathrm{F}_{\mathrm{i}}(\mathrm{K})\right\}$ and a set of design parameters $\left\{\mathrm{P}_{\mathrm{i}}\right\}$ that enable the recipe to be created. Figure 1 below synthesizes the proposed model.

C-K model

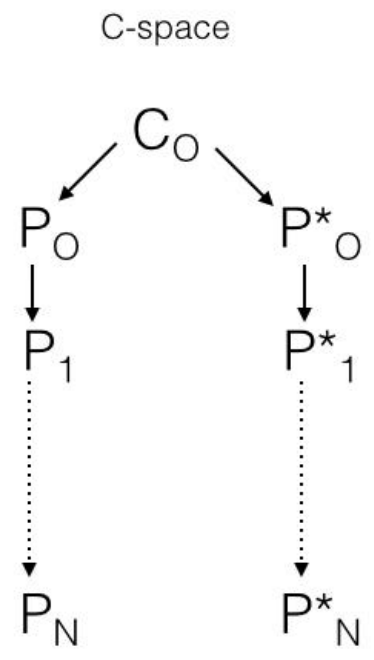

Suh Matrix

K-space

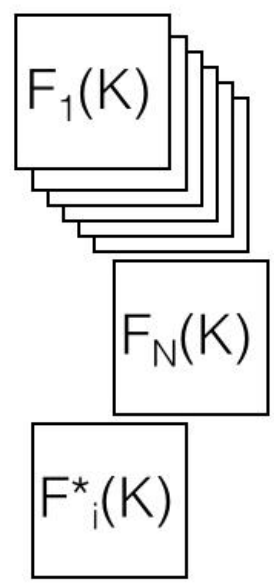

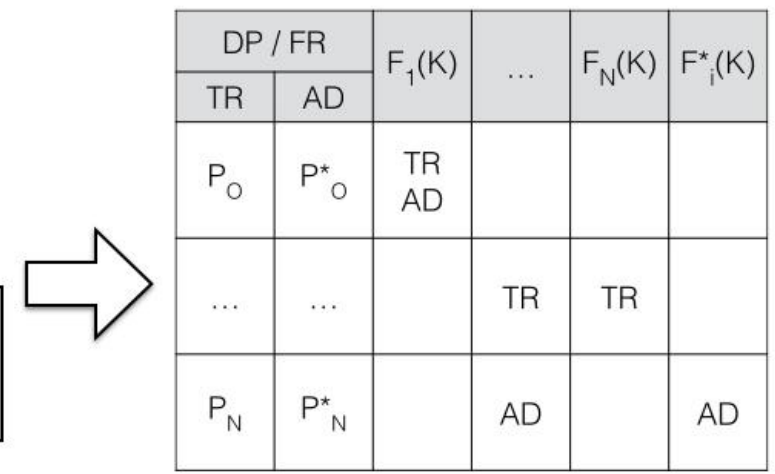

$\mathrm{C}_{0}$ : initial concept of the dish

$P_{i}$ : steps of the classic recipe

$P^{\star}$ : steps of the Ducasse recipe

$F_{i}(K)$ : functions to fulfill in the classic recipe

$\mathrm{F}^{\star}(\mathrm{K})$ : new functions not included in $\mathrm{F}_{\mathrm{i}}(\mathrm{K})$

Figure 1. Theoretical model of a classic and its reinterpretation

\section{Methodology}

\subsection{Data collection}

In this research, we focus on the design patternsof reinterpreting classic dishes: indeed, chefs might focus on classic dishes with the idea of a new, modern interpretation of the 
recipe. Such situations provide a useful space for analyzing chefs' design processes because classic recipes can be compared with recipes that represent the chef'sreinterpretation. As our study is exploratory in nature, a qualitative case study methodology is relevant because it provides a setting to study complex phenomena within their contexts (Baxter \& Jack, 2008). Indeed, as stated by Yin (2003), a case study design is critically relevant when the aim of the research conducted is to answer "how" and "why" questions. We therefore chose to focus on one specific chef but to analyze a set of 30 recipes from this particular chef, thus undertaking a single case study with embedded units (Yin, 2003). Because a researcher can only study a limited number of cases, it makes sense to select polar situations where the studied object may be more observable(Pettigrew, 1988; Eisenhardt, 1989). Such an approach is typically adopted when studying the chef FerranAdrià to investigate the role of entrepreneurs in initiating change (Svejenova, Mazza and Planellas, 2007).

Second, by relying on the analysis of recipes of dishes, we aim examining the final states of the design processes (which is encapsulated in the recipe) in order to show how some design operators must have been employed to realize this final state. Thus,we compareddifferent sets of recipes (the classics and those ofrenowned chef Alain Ducasse) to identify the diversity of means a chef uses to reinterpret a classic recipe.

We specifically chose to study Alain Ducasse for several reasons: first, Ducasse is considered to be one of the most famous chefs in the world. He won two Michelin stars in 1982 at the age of 26. In 1990, he received three stars for the Louis XV restaurant in Monaco, thus becoming the youngest chef to receive this highest honor. Currently managing multiple starredrestaurants, he holds 21 Michelin stars so far. The stability of managing and designing recipes for multiple restaurants also allows the opportunity to study a chef with a more stabilized design rationale. Second, we chose to focus on the work of Ducassebecause he is one of the few chefs who takesgreat care to explain his activities.In 1984, he was fortunate to survive a terrible plane crash; as a result, he had to manage his kitchen from his hospital bed 
for a number of months. This experience led him to truly think about transmitting culinary knowledge from a distance: as a consequence, he wrote many books and repeatedly described his own cooking process. He runs an editing firm for cooking books and a teaching institute. Therefore, his work can be analyzed through his writings.

We collected our data by gathering 60 recipes that were presented in two different books: "La Cuisine de reference" by Michel Maincent-Morel and "Le Grand Livre de Cuisine

- Bistrot, Brasserie et Restaurants de Tradition" by Alain Ducasse. The first is a basic teaching book in France and contains the standard recipes learned by every student in any cooking degree program in France; the second book has the same recipes reinvented by one of the most famous chefs in the world. We chose 30 dishes that were described and explained in both books. We built a comparative database of $2 \times 30$ recipes containing the following innovativeness variables: name of the recipe, percentage of changed ingredients, technical execution, production management, plate garnishing (or platingup), cost, dietetics, and the use of new technologies.

\subsection{Data analysis}

We analyzed our data in two steps. First, we conducted a qualitative analysis of our two sets of 30 recipes by modeling each recipe according tothe proposed framework. We then completed this first-order modeling with a quantitative research approach to identify the designpatterns and their uses in reinventing a cooking classic.

\subsubsection{Qualitative Analysis}

Our qualitative analysis aims to explain a chef's design methodology when he revisits arecipe from classic French cuisine. We performed a comparative analysis of the classic andreinvented recipes using the framework previously presented in Figure 1.

To make this comparison, we first modeled the reasoning that supported each recipe using a C-K theory diagram. We identified for each pair of recipes (classic andDucasse) the 
primary pockets of knowledge mobilized in the recipe to build the dish.A recipe is a sequence of basic, explicit tasks that are described to simplify the execution of a dish and decrease the level of knowledge required to produce the dish. It also includes the list of ingredients. First, we read through allof the ingredients lists and stepsinevery recipe to identify the types of culinary functions that could be relevant for coding a recipe. We obtained a list of 12 culinary functions:brightness, acidity, texture, freshness, fluidity, sourness, complexity, concentration, originality, garnish, aroma, and fineness. This list was validated by a French chef teaching at the Ducasse Institute as relevant functions to model recipes. Then, two independent coders used this set of 12 functions to identify which function was relevant in every recipe and to explicitly identify the links between one function and the relevant ingredients and/or the step(s) of execution of the recipe. The coders also provided a simplification of the steps in the recipe according to the different functions. Thus, the different steps in one recipe are described in the $\mathrm{C}$-space, and the $\mathrm{K}$-space represents a model of the primary functions used in the recipe, which are characterized as pieces of knowledge (see Figure 2).

We thenusedthe Suhmatrix to compare the traditional recipe with the revisited recipe by distinguishing the functions identified using $\mathrm{C}-\mathrm{K}$ theory. For each pair of recipes, we included as Functional Requirements the functions of the recipes and as Design Parameters the links between each function and the relevant ingredients and/or the step(s) of execution of the recipes.

\subsubsection{Quantitative Analysis}

Based on the first qualitative analysis, we conducted a quantitative analysis by searching for variables that could explain the different patterns highlighted by the qualitative analysis. We looked at the name of the recipe, the percentage of changed ingredients, the nature of the technical execution, the production process and management, the design of the platingup, the cost and the use of new technologies. 


\section{Results}

\subsection{Qualitative approach: modeling two sets of recipes}

We performed a comparative analysis of the two sets of recipes, first by using a C-K diagram to model each recipe andnext by using a Suhmatrix to compare the traditional recipe with the revisited one.

\subsubsection{Comparing recipes using a $C-K$ diagram}

To illustrate the use of $\mathrm{C}-\mathrm{K}$ theory, we will take one dish as an example: "Filets de barbue à la sauce Duglérée", which is a braised brill with shallot, onion, tomato, parsley and butter sauce. We first modeled the reasoning that supports each recipe using a $\mathrm{C}-\mathrm{K}$ diagram. According to the description found in cooking textbooks, "Filets de barbue à la sauceDuglérée" is cut fish fillets cooked in a sauce mounted with butter. This sauce is made from fish stock, white wine, chopped tomatoes, onions, chopped shallots and chopped parsley. From the traditional recipe, we highlighted the following functions of sauce Duglérée: brightness, acidity, fineness, complexity, Mediterranean freshness, and concentration.This analysis allows us to document the original concept behind the recipe for the traditional sauceDugléré, which ( $\mathrm{C} 0$ in the formalism of $\mathrm{C}-\mathrm{K}$ theory) takes the following form: "A fine, bright, concentrated, tangy and aromatic sauce for fish that inspires a complex Mediterranean freshness". Figure 3 shows a model using $\mathrm{C}-\mathrm{K}$ theory of the two recipes for"Filets de barbue à la sauce Duglérée": the recipe from "La Cuisine de reference" by Michel Maincent-Morel (in classic letters in Figure 3) and the recipe from "Le Grand Livre de Cuisine - Bistrot, Brasserie et Restaurants de Tradition" by Alain Ducasse (in italic bold letters in Figure2). 


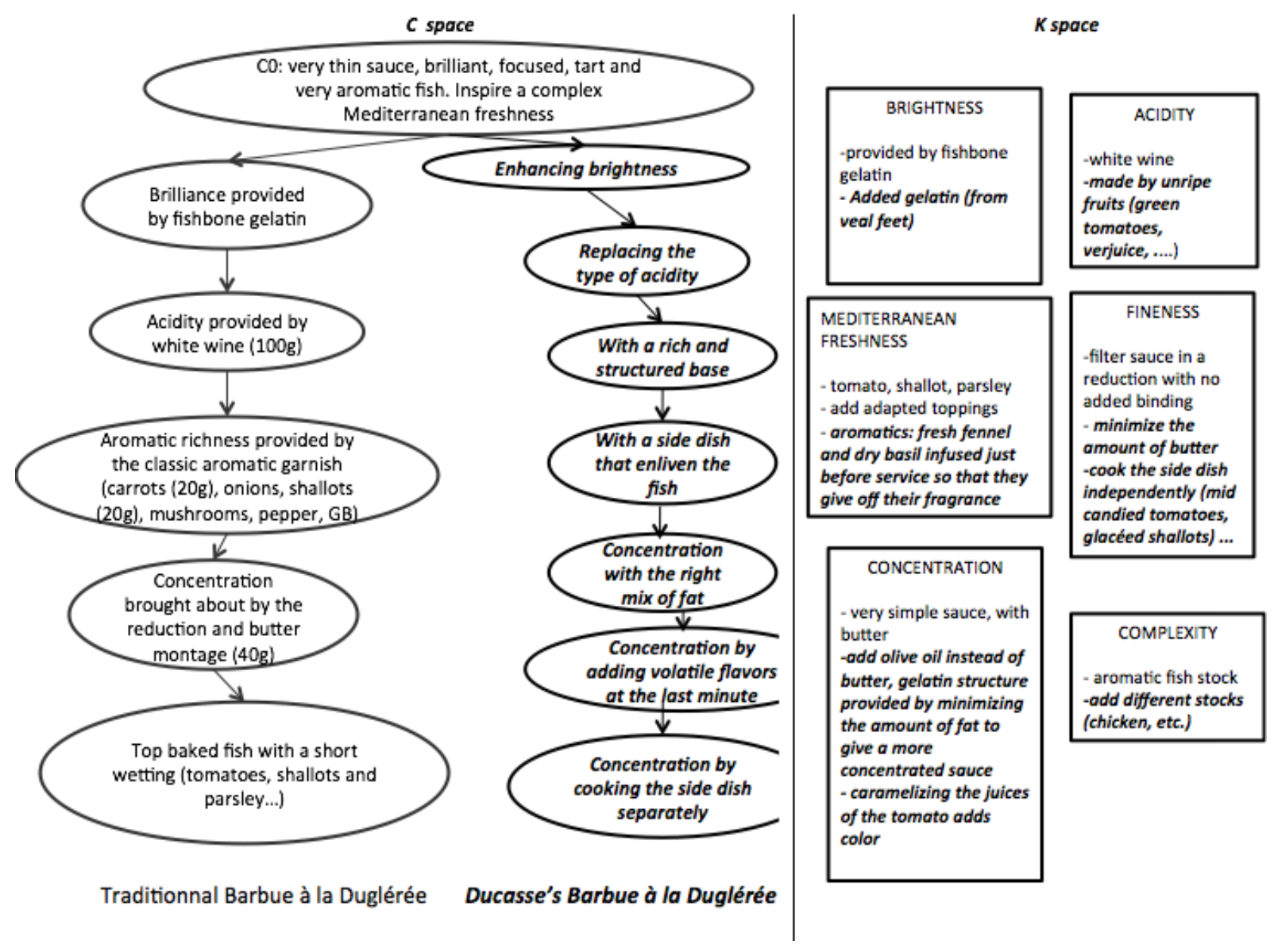

Figure 2. C-K model of the two recipes forBarbue à la sauce Duglérée: the different steps in one recipe are described in the C-space, and the K-space represents a model of the primary functions used in the recipe, which are characterized as pieces of knowledge.

The figure above shows that Alain Ducasse reinvented "Filets de barbue à la sauce Duglérée" byexpanding the initial concept using classic knowledge (for instance, using chicken stock as a base for a fish dish) and also by seeking or developing technical knowledge (for example,caramelizing the juices of the tomatoes to enrich the sauce). It can be noted that the two sauces are very different; however, they still share the same original concept, and as such,the dish is indeed a Filets de barbue à la Duglérée in both cases: the two recipes not only share the same namebut are two interpretations of the same dish. 
We then used an axiomatic design approach to compare the traditional recipe with the revisited recipe. Our results show that there are actually two types of comparisons that can be made, which we will illustrate with two examples, "Pouletgrillé à l'Américaine" and "Fricassée de volaille à l'ancienne".

For the first recipe, "Pouletgrillé à l'Américaine", building on the $\mathrm{C}-\mathrm{K}$ diagram presented earlier, four functional requirements can be identified: texture, acidity, aroma and garnish. The design parameters are also described using the $\mathrm{C}-\mathrm{K}$ diagram, which allowsus tobuild the following comparative Suh matrix (see Table 1).

Table 1. Comparative Suhmatrix for Pouletgrillé à l'Américaine

\begin{tabular}{|c|c|c|c|c|c|}
\hline \multicolumn{2}{|c|}{ Design parameters } & \multirow[b]{2}{*}{ Texture } & \multirow[b]{2}{*}{ Acidity } & \multirow[b]{2}{*}{ Aroma } & \multirow[b]{2}{*}{ Garnish } \\
\hline Traditional recipe (TR) & Ducasserecipe (AD) & & & & \\
\hline $\begin{array}{l}\text { Give the sauce extra } \\
\text { thickness and shine by } \\
\text { mounting with butter }\end{array}$ & $\begin{array}{l}\text { Less fat without losing } \\
\text { creamy texture. The sauce } \\
\text { is not mounted with butter, } \\
\text { but retains its consistency }\end{array}$ & $\begin{array}{l}\text { TR } \\
\mathrm{AD}\end{array}$ & & & \\
\hline A variety of garnishes & Original recipe ingredients & & $\begin{array}{l}\mathrm{TR} \\
\mathrm{AD}\end{array}$ & & \\
\hline $\begin{array}{l}\text { The acidity is provided by } \\
\text { vinegar, tomato paste and } \\
\text { white wine balanced with } \\
\text { thyme and bay leaves }\end{array}$ & $\begin{array}{c}\text { Reduce acidity by cooking } \\
\text { the tomatoes with wine and } \\
\text { vinegar (which dilutes the } \\
\text { mixture) }\end{array}$ & & & $\begin{array}{l}\text { TR } \\
\text { AD }\end{array}$ & \\
\hline $\begin{array}{l}\text { Paris mushrooms, tomato, } \\
\text { peanut oil, bacon and } \\
\text { potato provide garnish }\end{array}$ & $\begin{array}{l}\text { The garnish is slightly } \\
\text { simpler and classic but } \\
\text { retains most of the original } \\
\text { ingredients }\end{array}$ & & & & $\begin{array}{l}\text { TR } \\
\text { AD }\end{array}$ \\
\hline
\end{tabular}

Although Alain Ducasse innovated the method with which the sauce and the garnish are prepared by defining new design parameters, he did not change the recipe's functions. Both the traditional and the reinterpreted versions of "Pouletgrillé à l'Américaine"address the same functions, but in different ways. Ducassein fact proposed new design parameters in his recipe to achieve the traditional functions of "Pouletgrillée à l'Américaine”. 
For the second recipe, the "Fricassée de volaille à l'ancienne", building on the C-K diagram, five functional requirements can be identified for the traditional recipe: concentration, acidity, brightness, aroma and garnish. However, when examiningDucasse's recipe, a new functional requirement emerges: freshness, which is provided by the tomato juice. The design parameters are also described using the C-K diagram, which allowsus to build the following comparative Suh matrix (see Table 2).

Table 2. Comparative Suhmatrix for the Fricassée de volaille à l'ancienne

\begin{tabular}{|c|c|c|c|c|c|c|c|}
\hline \multicolumn{2}{|c|}{ Design parameters } & \multirow[b]{2}{*}{$\begin{array}{c}\text { Concent } \\
\text { ration }\end{array}$} & \multirow[b]{2}{*}{$\begin{array}{l}\text { Brightn } \\
\text { ess }\end{array}$} & \multirow[b]{2}{*}{ Acidity } & \multirow[b]{2}{*}{ Aroma } & \multirow[b]{2}{*}{ Garnish } & \multirow[b]{2}{*}{$\begin{array}{c}\text { Freshne } \\
\text { ss }\end{array}$} \\
\hline $\begin{array}{l}\text { Traditional } \\
\text { recipe (TR) }\end{array}$ & $\begin{array}{c}\text { Ducasse recipe } \\
\text { (AD) }\end{array}$ & & & & & & \\
\hline $\begin{array}{l}\text { Using velouté } \\
\text { (double cream } \\
\text { and flour) and } \\
\text { baking the } \\
\text { chicken stock }\end{array}$ & $\begin{array}{c}\text { Cooking over low } \\
\text { heat }\end{array}$ & $\begin{array}{l}\mathrm{TR} \\
\mathrm{AD}\end{array}$ & & & & & \\
\hline Butter & Butter and olive oil & & $\begin{array}{l}\mathrm{TR} \\
\mathrm{AD}\end{array}$ & & & & \\
\hline $\begin{array}{c}\text { The lemon adds a } \\
\text { touch of acidity } \\
\text { to the } \\
\text { mushrooms }\end{array}$ & $\begin{array}{l}\text { Dashes of vinegar } \\
\text { and wine are added } \\
\text { to the cookingsauce }\end{array}$ & & & $\begin{array}{l}\mathrm{TR} \\
\mathrm{AD}\end{array}$ & & & \\
\hline $\begin{array}{l}\text { Varied aromatic } \\
\text { garnish (celery- } \\
\text { filled bouquet } \\
\text { and cloves) }\end{array}$ & $\begin{array}{l}\text { Thyme, bay leaf } \\
\text { and parsley }\end{array}$ & & & & $\begin{array}{l}\mathrm{TR} \\
\mathrm{AD}\end{array}$ & & \\
\hline \multirow[t]{2}{*}{$\begin{array}{l}\text { Paris mushrooms } \\
\text { as garnish, with } \\
\text { small onions and } \\
\text { granulated sugar }\end{array}$} & & & & & & TR & \\
\hline & Tomato juice & & & & & & $\mathrm{AD}$ \\
\hline
\end{tabular}

In this second example, Ducasse removed the function Garnish to focus on the meat taste and added the function Freshness. He decided to change the set of functions by removing a functional requirement (the side dish) and adding a new function (the freshness provided by 
the tomato suc). To achieve the different functional requirements, he used new design parameters as well by changing the ingredients and the techniques used to integrate them.

\subsubsection{Conclusion of the qualitative analysis}

Our qualitative analysis highlights two design regimesused by Alain Ducasse to reinterpret traditional recipes by focusing on the nature of the set of functions a recipe aims to fulfill. The first regimeconsists of maintaining the same functions of the original recipe while changing the means to achieve them. The second requires changing the set of functions by removing or adding new ones and occasionally designing new ways to achieve these functions. From the 30 recipes we studied, the first regime (new design parameters, same functional requirements) was used for 17 recipes; the second regime (new design parameters, new functional requirements) was used for 13 recipes.

\subsection{Quantitative results}

Based on the initial results provided by the qualitative analysis, we conducted a quantitative analysis by searching for variables that could explain the two regimeshighlighted by the qualitative analysis. The studied variables are the following: name of the recipe, percentage of changed ingredients, technical execution, production management, platingup, cost, and the use of new technologies.

We conducted a one-factor ANOVA to determinethe explanatory factors of the two strategies previously identified. Our results show that both the change in the recipe name $(\mathrm{p}=0.02)$ and the change in the technical execution $(\mathrm{p}=0.008)$ are correlated to strategy 2 (new design parameters, new functional requirements). Indeed, when a chef reinterprets a traditional dish by aiming to fulfill new functions, he tends to change the recipe's name and the techniques he uses for the reinterpretation. For instance, in the example presented in the qualitative analysis, the Fricassée de volaille, Ducasse's recipe is entitled Fricassée de volaillefermière au vinaigre, and the recipe requires cooking the chicken slowly for more than 
2 hours rather than the 25 minutes in the classic recipe. The percentage of changes in the ingredient list also tends to correlate to the choice of strategy but is not significant $(\mathrm{p}=0.07)$. None of the other studied variables (technical execution, production management, platingup, cost, and the use of new technologies) correlate (see Table 3).

Table 3. ANOVAresults

\begin{tabular}{|c|c|c|c|c|c|c|c|}
\hline & $\begin{array}{c}\text { Change of } \\
\text { name }\end{array}$ & $\begin{array}{c}\text { Change of } \\
\text { ingredients }\end{array}$ & $\begin{array}{c}\text { Change of } \\
\text { technique }\end{array}$ & $\begin{array}{c}\text { New } \\
\text { production } \\
\text { management }\end{array}$ & $\begin{array}{c}\text { New } \\
\text { platingup }\end{array}$ & $\begin{array}{c}\text { Increase in } \\
\text { cost }\end{array}$ & $\begin{array}{c}\text { Innovative } \\
\text { technique }\end{array}$ \\
\hline $\mathrm{p}$ & 0.02 & 0.073 & 0.0078 & 0.36 & 0.104 & 0.39 & 0.21 \\
\hline
\end{tabular}

The quantitative research thus allowed us to identify two variables that explained the two different design strategies. When the strategy consists of keeping the same recipe functions, the name and the technique used by the chef are the same, whereas they evolve when the design strategy consists of not only finding new design parameters to address existing functional requirements but also changing the set of functions (by adding and/or removing them).

\section{Discussion}

Our study showed that reinventing a recipe is not a coincidence but a methodological process used by chefs. Two different design regimeswere identified using a framework that builds on a comparison of design outputs (recipes) using axiomatic design modeling, for which the functional requirements come from a modeling of the functions encapsulated in recipes using $\mathrm{C}-\mathrm{K}$ theory. The first design strategy consists of retaining the same functions for the recipes but changing the ingredients and/or the technical execution. The second strategy requires changing the functions by removing the existing functions and/or adding new ones while alsochanging other elements such as the ingredients or the technical execution. This finding is in line with the work of Pretuzelli andSavino $(2012,2013)$, who argued that in reinterpreting a classic, there are two primary strategies: either combining old components 
with novel ones (i.e., finding new design parameters)or developing unusual recombinations(i.e., developing new functional requirements).

\subsection{Insights into chefs' creative processes: the interaction of the techniques and functions behind the recipes}

The start of a culinary innovation process is generally characterized as an "idea generation" phase (Ottenbacher \& Harrington, 2007; Horn \& Hu, 2008), during which a chef acquires creative thinking skills by producing harmonious and tasty combinations of ingredients and ideas. However, scholars have recently noted that this view is built on a representation of cooking as consisting of well-structured tasks rather than ill-structured problems (Stierand, Lynch \& Dörfler, 2011). Thus, recent research has focused either on the art of culinary innovation (Stierand \& Lynch, 2008; Kretschmera, 2001) byidentifying how cooks and chefs exploit product seasonality as well as diverse sources of inspiration for designing new dishes, or on culinary creativity, which is perceived as a mix of personal identity, motivation, mood, and professional knowledge and experience (Horng\& Lee, 2006). However, these insights into how chefs innovate in their cooking do not provide a broad model of the early phase of culinary innovation: idea generation. Our dual model contributes to filling this gap by clarifying the mechanisms used by chefs to create a new dish from a classic and specifically highlighting the critical role of functions. The reluctance of researchers within creative industries and applied arts to use the notion of function may lie in the fact that the concept of function has historically been associated with the rationalist perception that functions are objectified and quantified measures of design. This restriction does not apply in a design theory model: indeed, a "function" can be defined in the broadest possible way as "a judgment strategy" or "desirability". We retain the idea of function as a value operator, which allows for the formulation of ideals, expectations, etc. Our results thus provide an opportunity to address the ambiguity in the current review of Alain 
Ducasse'scuisine. Indeed, food critics have characterized the work of Ducasse as conveying respect for the "product" by eliminating superfluous elements while maintaining an influence from Mediterranean cuisine that represents a refinement and perfection of the French culinary tradition. We showed that this simplification undertaken by Ducasse is dual: in the means he uses to build a recipe and in the innovative will embedded in the functions he wants the recipe to fulfill.

More generally than in the field of culinary design, our framework suggests that the analysis of functions and their dynamics is at the core of understanding design, trends and the role that designers can play in the evolution of tradition. Because it remains tremendously complex for chefs to extend culinary techniques - apart perhaps from FerranAdrià - the devices they have at their disposal to differentiate themselves lie in inventing new culinary functions, which in turn define new culinary styles. This statement can be generalized to different areas of design: functions are crucial to the design process, and creating a new object will make known functions evolve and new functions emerge.

\subsection{Reinventing classics: a dual strategic design process}

Our research has highlighted the diversity of functions that a recipe can fulfill and the scope of imagination and evocation these functions can embed. Therefore, reinterpreting a traditional dish is not only a matter of using new or old components but also of redefining how a recipe is imagined in terms of taste, flavor, softness, acidity, freshness, etc. In the first design strategy, reinventing a classic means following the existing rules while exploring spaces within a traditional perspective. The aim is to work within the dish's stable identity and, generally, to introduce a rare element (a new ingredient, for instance). Thisregime is in line with research that hasemphasized the importance of studying gastronomic identity, which illustrates the influences of the environment (geography and climate) and culture (history and ethnic influences) on prevailing taste components, textures and flavors in food and drink 
(Harrington, 2006). In the second design regime, adding a new function-for instance, "freshness" in a "Fricassée de volaille"—-may appear to be odd at first as well as nonsignificant. However, it is a very surprising addition to a recipe:freshness is a function that is traditionally associated with other types of dishes. Such design strategies actually reveal a chimera-forming process, i.e., the partial definition of a new object by its unexpected attributes (Hatchuel, Le Masson \& Weil; 2013), which can be consideredheretical in terms of existing knowledge.

In a more general context than the specific field of culinary design, our study supports the proposition of a dual design process in the reinvention of classics; we propose two different design regimesthat characterize the reinterpretation of a traditional object. These two design regimesrelate to Gero's (1990) model, which established two broad classifications of design patterns: routine and non-routine. In routine designing, all of the different elements are known and already available; this approach characterizes the pure repetition of existing recipes with different degrees of talent. In contrast, in non-routinedesigning, exploration is useful for simultaneously finding the "best" space for possible designs and the "best" design possible in that space. Thus, our two design regimesoffer two different facetsto this second design pattern, which suggeststhat Gero's design patternscan be integrated with Hatchuel and Weil's proposal of two design regimes - rule-based and innovative (Hatchuel\& Weil, 2009).Nonroutine design thus relates to either rule-based design,in which the primary functions of the original object remain stable,or innovative design,in which a designer, to reinterpret a classic, changes the original's set of functions by removing and/or adding new functions while exploring new means to fulfill this new set of functions.

Our theoretical framework provides a means to further study this dual regime of reinterpreting tradition by integrating a model that evaluates a finished design (using the Suh matrix from axiomatic design theory) and a model that supports the elicitation of the 
knowledge associated with any design reasoning, thus helping to identify functional requirements in situations where they are not explicit but rather embedded in the final design.

\subsection{Implications for including temporal dimensions in the study of design processes}

Our results suggest that to reinterpret the tradition, it is not necessary to challenge the identity of the tradition. In the gastronomic field, which is a traditional art, staying within known spaces can foster extreme creativity. In a traditional art, the disruptive creation may be a dangerous strategy because if the designer goes too far from the classical canons, he/she risks losing the audience. The challenge then becomes to conduct innovative explorations of potentially creative neighborhoods (in the mathematical sense) of tradition. The idea is thus to identify the attribute(s) that may cause a sublimation of the object without changing its identity too strongly. Introducing green tomato in a sauce recipe for the "Bar à la Duglérée" is staying within the tradition while introducing a disruptive element that lifts up the dish and gives it a distinct, unique, innovative flavor.

Our research is a small step in the direction of reconciling the importance of both creation and imitation, tradition and innovation in design in general. As stated by Jauss (1988), the failure to recognize innovation and tradition as two facets of art"has plunged both traditionalism and modernism into ahistoricaldogmatism". Indeed, traditional design is usually blind to the role of innovation while modern design is solely focus on the new, leading to the difficulty to envision design as the creative interplay between the two (ibid). Beyond the sole domain of culinary design, our resultsclarify an artistic strategy that may be qualified as the "design of creative traditionalism".Ducasse's green tomato echoes the red buoy of Joseph Turner: in 1832, when exposing a serene seascape painting ("Helvoetsluys", a quite classic marine painting), Turner stole the show with a single daub of red paint. Seeing that in comparison with John Constable's "Opening of Waterloo Bridge", his own painting was slightly lacking in color, Turner painted a small red spot in the middle of his already 
hangedcanvas. This small addition completely changed the way the audience saw Turner's painting, which was a great success. Once again, by innovating within tradition and changing one attribute while staying within the identity of the object, creative traditionalism can be achieved.

By focusing on eliciting functions within designs, our model allows us to highlight the value added by design strategies in creative settings. Indeed, in fields that hold a strong attachment to tradition, such as cooking but also opera or classic theater, functions may be proxies to investigate design strategies that aim to create radically new objects that hold traditional and classical value from the start. For instance, how does one design a new classic in the fashion industry? How does one write a classic new theater play? An empirical study on the emergence of new traditional arts such as the Portuguese music genre Fado suggests the interesting notion of the contemporary-driven tradition (Hatchuel, 2011). Such a design strategy has strong contemporary value, as it characterizes a form of nostalgic design that triggers emotions and awakens memories.

\section{Conclusion: limitations and perspective}

Within the limitations of our data sample (30 dishes, 1 chef), we were able to model the different regimesinvolved in reinventing classics. This model could be used to reinterpret other chefs' processes. However, following our methodological approach, this would require identifying chefs who publish recipes of reinvented versions of traditional dishes. We applied this approach to the starred chef YannickAlleno: we found only 7 recipes matching our protocol (in the book "TerroirParisien"), for which only one design strategy was deployed.

In addition, more qualitative research on the ongoing processes of reinventing classics could explore the dimensions of reinterpreting tradition, which remain to be studied. Typically, analyzing the capacity of designers (or chefs) to interpretan unexpected discovery 
(Kelly \&Gero, 2014) that may arise from reinvention may be a basis for discussing the blurred barrier between reinventing a classic and designing a truly new object that departs from the work on an existing classic. Many fascinating questions remain to be explored regarding the design process in itself: How are new designs developed and tested? Is it a collective and/or an individual process? Do chefs use taste panels, colleagues or their own evaluations? How are prototypes and tests handled? Are there user-centered design processes?

Finally, our findings highlight the relevance of design theories to understanding art design by stressing the importance of studying the different strategies for renewing functions within a specific domain. The extension of our framework to reinventing classics in other domains and also to innovation processes in artistic domains in general may suggest that the capacity to innovate relies on the ability to create value by sustaining function renewal. Thus, expanding our framework to other cases of reinterpreting traditional objects (within and outside of the culinary world) would contribute to clarifying the stakes of managing tradition within innovative design in other fields.

\section{References}

Agogué, M. \&Kazakçi, A. (2014), 10 Years of C-K Theory: A Survey on the Academic and Industrial Impacts of a Design Theory in An Anthology of Theories and Models of Design (edsChakrabarti, A. \& Blessing, L.). Springer, 219-235.

Brown, S., Kozinets, R. V., \& Sherry, J. F. (2003). Sell me the old, old story: retromarketing management and the art of brand revival. Journal of Customer Behaviour, 2(2), 133-147.

Capaldo, A., Lavie, D., \&Petruzzelli, A. M. (in press). Knowledge Maturity and the Scientific Value of Innovations The Roles of Knowledge Distance and Adoption. Journal of Management

Faerber, S. J., \& Carbon, C. C. (2013). Jump on the innovator's train: cognitive principles for creating appreciation in innovative product designs. Research in Engineering Design, 24(3), 313-319. 
Gero, J. S. (1990). Design prototypes: a knowledge representation schema for design. $A I$ magazine, 11(4), 26.

Harrington, R.J. (2004) The Culinary Innovation Process - A Barrier to imitation.Journal of Foodservice Business Research, Vol7 p. 337-350

Harrington, R. J. (2006). Defining gastronomic identity: The impact of environment and culture on prevailing components, texture and flavors in wine and food. Journal of Culinary Science \& Technology, 4(2-3), 129-152.

Hatchuel, A., \& Weil, B. (2009). C-K design theory: An advanced formulation. Research in Engineering Design, 19, 181-192.

Hatchuel, A. (2013). Deconstructing meaning: Industrial design as Adornment and Wit. In Crafting the Future: Proceedings of the 10th European Academy of Design Conference.

Hatchuel, A., Weil, B., \& Le Masson, P. (2013). Towards an ontology of design: lessons from $\mathrm{C}-\mathrm{K}$ design theory and Forcing. Research in engineering design, 24(2), 147163.

Hatchuel, G. (2011). Observer le processus de contemporéanisation des arts traditionnels. Master thesis

Horng, J. S., \& Hu, M. L. (2008). The mystery in the kitchen: Culinary creativity. Creativity Research Journal, 20(2), 221-230.

Horng, J. S., \& Lee, Y. C. (2006). What does it take to be a creative culinary artist?. Journal of culinary science and technology, 5(2-3), 5-22.

Jauss, H. R. (1988). Tradition, innovation, and aesthetic experience.Journal of Aesthetics and Art Criticism, 375-388.

Katila, R., \&Ahuja, G. (2002). Something old, something new: A longitudinal study of search behavior and new product introduction. Academy of management journal, 45(6), 11831194.

Katila, R. (2002). New product search over time: past ideas in their prime?Academy of Management Journal, 45(5), 995-1010.

Kelly, N., \&Gero, J. S. (2014). Interpretation in design: modelling how the situation changes during design activity. Research in Engineering Design, 25(2), 109-124.

Kretschmera, KE. (2001): Culinary innovation, love, and the social organization of learning in a West African city. Food and Foodways: Explorations in the History and Culture of Human Nourishment, Vol 9 issue 4. 
Kroll, E., Le Masson, P., \& Weil, B. (2014). Steepest-first exploration with learningbased path evaluation: uncovering the design strategy of parameter analysis with $\mathrm{C}-\mathrm{K}$ theory. Research in Engineering Design, 25(4), 351-373.

Le Masson, P., Weil, B., \&Hatchuel, A. (2010). Strategic management of innovation and design. Cambridge: Cambridge University Press.

Leschziner, V. (2009). Cooking logics: Cognition and reflexivity in the culinary field. In symposium on globalization, food and social identities in the Pacific Region, Sophia University, February (pp. 21-22).

Majchrzak, A., Cooper, L. P., \&Neece, O. E. (2004). Knowledge reuse for innovation. Management science, 50(2), 174-188.

MesseniPetruzzelli Antonio, T;Savino (2013) Reinterpreting tradition to innovate: the case of italian haute cuisine, 20th International Product Development Management Conference.

MesseniPetruzzelli A., Savino T., (2012). Search, Recombination, and Innovation: Lessons from Haute Cuisine, Long Range Planning, http://dx.doi.org/10.1016/j.lrp.2012.09.001

MesseniPetruzzelli A., Rotolo, D., \& Albino, V. (2012). The impact of old technologies on innovation: the case of the US biotechnology industry. Technology Analysis \& Strategic Management, 24(5), 453-466.

Nelson, R., Winter, S., 1982. An Evolutionary Theory of Economic Change. Harvard University Press, Cambridge.

Nerkar, A. (2003). Old is gold? The value of temporal exploration in the creation of new knowledge. Management Science, 49(2), 211-229.

Ottenbacher, M ; Harrington, RJ. (2007a) The innovation development process of Michelin-starred chefs.International Journal of Contemporary Hospitality Management, Vol19 p. 444-460

Ottenbacher, M ; Harrington, RJ (2007b): The Culinary Innovation Process. Journal of Culinary Science \& Technology, Vol 5 issue 4.

Ottenbacher, M; Harrington, RJ (2008): U.S. and German Culinary Innovation Processes: Differences in Involvement and Other Factors Journal of Foodservice Business Research, Vol 11 issue 4.

Rao, H., Monin, P., \& Durand, R. (2005). Border crossing: Bricolage and the erosion of categorical boundaries in French gastronomy. American Sociological Review, 70(6), 968-991. 
Reich, Y., Hatchuel, A., Shai, O., \&Subrahmanian, E. (2012). A theoretical analysis of creativity methods in engineering design: casting and improving ASIT within C-K theory. Journal of Engineering Design, 23, 137-158.

Ruiza,J ; Calvarroa, J ;Sánchez J ; Roldána , M (2013) : Science and Technology for New Culinary Techniques.Journal of Culinary Science \& Technology, Vol 11, Issue: Creativity and Innovation in Haute Cuisine.

Sarkar, P., \&Chakrabarti, A (2014). Ideas generated in conceptual design and their effects on creativity. Research in Engineering Design, 25, 185-201.

Stierand, M ;Lynch ,P. (2008): The Art of Creating Culinary Innovations Tourism and Hospitality research, Vol 8 p. 337-350.

Stierand, M; Lynch, P; Dörfler ,V. (2009) Innovation of Extraordinary Chefs: Development Process or Systemic Phenomenon : Conference, 15-17 September, Brighton.

Suh, N. P. (2001). Axiomatic design: advances and applications (Vol. 4). New York: Oxford university press.

Svejenova, S., Mazza, C., \&Planellas, M. (2007). Cooking up change in haute cuisine: FerranAdrià as an institutional entrepreneur. Journal of Organizational Behavior, 28(5), 539561.

Taura, T., \& Nagai, Y. (2013). A systematized theory of creative concept generation in design: first-order and high-order concept generation. Research in Engineering Design, 24(2), 185-199. 